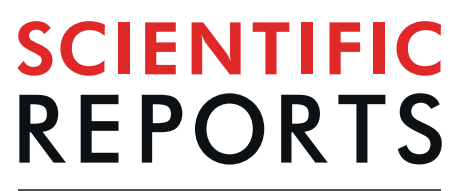

natureresearch

Check for updates

\title{
Controlling oxygen coordination and valence of network forming cations
}

\author{
Takuya Aoyagi ${ }^{1,2} \bowtie$, Shinji Kohara ${ }^{3,4,5,6 凶}$, Takashi Naito $^{1}$, Yohei Onodera ${ }^{7,4}$, \\ Motomune Kodama ${ }^{1}$, Taigo Onodera ${ }^{1}$, Daiko Takamatsu ${ }^{1}$, Shuta Tahara ${ }^{8,4}$, Osami Sakata $\mathbb{D}^{3}$, \\ Tatsuya Miyake ${ }^{1}$, Kentaro Suzuya ${ }^{9}$, Koji Ohara $\mathbb{D}^{6}{ }^{6}$, Takeshi Usuki ${ }^{10}$, Yamato Hayashi ${ }^{2}$ \& \\ Hirotsugu Takizawa
}

Understanding the structure-property relationship of glass material is still challenging due to a lack of periodicity in disordered materials. Here, we report the properties and atomic structure of vanadium phosphate glasses characterized by reverse Monte Carlo modelling based on neutron/synchrotron X-ray diffraction and EXAFS data, supplemented by Raman and NMR spectroscopy. In vanadium-rich glass, the water durability, thermal stability and hardness improve as the amount of $\mathrm{P}_{2} \mathrm{O}_{5}$ increases, and the network former of the glass changes from $\mathrm{VO}_{x}$ polyhedra to the interplay between $\mathrm{VO}_{x}$ polyhedra and $\mathrm{PO}_{4}$ tetrahedra. We find for the first time that the coordination number of oxygen atoms around a V ${ }^{4+}$ is four, which is an unusually small coordination number, and plays an important role for water durability, thermal stability and hardness. Furthermore, we show that the similarity between glass and crystal beyond the nearest neighbour distance is important for glass properties. These results demonstrate that controlling the oxygen coordination and valence of the network-forming cation is necessary for designing the properties of glass.

Oxide glass components are basically classified into network formers, network modifiers and intermediates by Zachariasen ${ }^{1}$ and Sun $^{2}$. Typical network formers satisfy Zachariasen's rules ${ }^{1}$, but $\mathrm{V}_{2} \mathrm{O}_{5}$ is classified as a network former ${ }^{1}$ or intermediate ${ }^{3}$. This is because it is hard for this oxide to form glass on its own because the oxygen coordination number is five in a crystalline phase, which is larger than the coordination number of typical network formers of three and four. $\mathrm{V}_{2} \mathrm{O}_{5}$ based glasses have been widely studied for decades because $\mathrm{V}_{2} \mathrm{O}_{5}$ glass is a typical semiconducting glass originating from hopping conduction. Indeed, not only fundamental research on electrical properties ${ }^{4-8}$ but also applied research on cathode materials for lithium, sodium and magnesium ion batteries have been reported ${ }^{9-12}$. This glass also has a low glass transition temperature and relatively low thermal expansion $^{4}$. These are quite attractive properties for low-melting glass used for sealing. In this field, lead borate glass with a high percentage of $\mathrm{PbO}$ has been applied to sealing below $400^{\circ} \mathrm{C}$ in electronic devices, such as IC ceramic packages, crystal oscillators and micro-electro-mechanical systems. Since lead components are a hazardous substance for human health and the environment, it is necessary to avoid the use of $\mathrm{PbO}$, and hence, $\mathrm{V}_{2} \mathrm{O}_{5}$ based glass is a promising material for overcoming this problem ${ }^{13-19}$. However, there are two critical problems that face the practical application of $\mathrm{V}_{2} \mathrm{O}_{5}$ based glass: poor water durability and low thermal stability.

${ }^{1}$ Hitachi Research Laboratory, Hitachi Ltd., 7-1-1 Omika, Hitachi, Ibaraki, 319-1292, Japan. ${ }^{2}$ Tohoku University, 66-07 Aoba-yama, Sendai, Miyagi, 980-8579, Japan. ${ }^{3}$ Light/Quantum Beam Field, Research Center for Advanced Measurement and Characterization, National Institute for Material Science (NIMS), 1-1-1 Kouto, Sayo-cho, Sayogun, Hyogo, 679-5148, Japan. ${ }^{4}$ Center for Materials Research by Information Integration $\left(\mathrm{CMI}^{2}\right)$ Research and Services Division of Materials Data and Integrated System (MaDIS), NIMS, 1-2-1 Sengen, Tsukuba, Ibaraki, $305-$ 0047, Japan. ${ }^{5}$ PRESTO, Japan Science and Technology Agency, 7 Gobancho, Chiyoda-ku, Tokyo, 102-0076, Japan. ${ }^{6}$ Diffraction and Scattering Division, Japan Synchrotron Radiation Research Institute/SPring-8, 1-1-1 Kouto, Sayocho, Sayo-gun, Hyogo, 679-5198, Japan. ' Institute for Integrated Radiation and Nuclear Science, Kyoto University, 2-1010 Asashiro-nishi, Kumatori-cho, Sennan-gun, Osaka, 590-0494, Japan. ${ }^{8}$ University of the Ryukyus, 1 Senbaru, Nishihara-cho, Okinawa, 903-0213, Japan. ${ }^{9}$ Japan Atomic Energy Agency/J-PARC, 2-4 Shirakata, Tokai-mura, Nakagun, Ibaraki, 319-1195, Japan. ${ }^{10}$ Yamagata University, 1-4-12 Kojirakawa-machi, Yamagata-shi, 990-8560, Japan. 凶e-mail: takuya.aoyagi.ga@hitachi.com; KOHARA.Shinji@nims.go.jp 


\begin{tabular}{|c|c|c|c|c|c|c|c|c|c|}
\hline \multirow{2}{*}{$\begin{array}{l}\text { Sample } \\
\text { No. }\end{array}$} & \multicolumn{2}{|c|}{ Composition $/ \mathrm{mol} \% \pm 0.5$} & \multirow{2}{*}{$\begin{array}{l}{\left[\mathrm{V}^{4+}\right] /\left[\mathrm{V}_{\text {total }}\right]} \\
\pm 0.02\end{array}$} & \multirow{2}{*}{$\begin{array}{l}\text { Density } / \mathrm{g} \mathrm{cm}^{-3} \\
\pm 0.0004\end{array}$} & \multirow{2}{*}{$\begin{array}{l}\text { Atomic number } \\
\text { density/atom } \AA^{-3}\end{array}$} & \multirow{2}{*}{$\begin{array}{l}\text { Melting } \\
\text { temperature } /{ }^{\circ} \mathrm{C}\end{array}$} & \multicolumn{3}{|c|}{ Thermal stability $/{ }^{\circ} \mathrm{C} \pm 2$} \\
\hline & $\mathrm{V}_{2} \mathrm{O}_{5}$ & $\mathrm{P}_{2} \mathrm{O}_{5}$ & & & & & $T_{\mathrm{g}}$ & $T_{\mathrm{c}}$ & $\Delta T$ \\
\hline VP10 & 90.2 & 9.8 & 0.06 & 2.9712 & 0.0702 & 900 & 224 & 253 & 29 \\
\hline VP19 & 81.0 & 19.0 & 0.14 & 2.9315 & 0.0705 & 950 & 244 & 379 & 135 \\
\hline VP28 & 71.5 & 28.5 & 0.24 & 2.8926 & 0.0709 & 1000 & 280 & 420 & 140 \\
\hline VP37 & 63.5 & 37.5 & 0.38 & 2.8691 & 0.0716 & 1000 & 348 & 545 & 197 \\
\hline VP44 & 55.8 & 44.2 & 0.57 & 2.8613 & 0.0723 & 1150 & 413 & None & None \\
\hline
\end{tabular}

Table 1. Composition and properties of VP $x$ glasses.

Several components, i.e., $\mathrm{P}_{2} \mathrm{O}_{5}, \mathrm{TeO}_{2}, \mathrm{GeO}_{2}, \mathrm{BaO}$ and $\mathrm{PbO}$, can vitrify $\mathrm{V}_{2} \mathrm{O}_{5}$ in binary systems ${ }^{4}$. Above all, the most common vitrification component is $\mathrm{P}_{2} \mathrm{O}_{5}$ because the $\mathrm{V}_{2} \mathrm{O}_{5}-\mathrm{P}_{2} \mathrm{O}_{5}$ system has the widest range of vitrification in binary systems. Moreover, the properties of this binary system change drastically with the amount of $\mathrm{P}_{2} \mathrm{O}_{5}$ compared with other components ${ }^{20,21}$. For example, the glass transition temperature increases about $200^{\circ} \mathrm{C}$, the electrical resistivity increases to the double-digit range, and water resistance improves from water soluble to nearly insoluble in the composition range from $80 \mathrm{~V}_{2} \mathrm{O}_{5}-20 \mathrm{P}_{2} \mathrm{O}_{5}$ to $50 \mathrm{~V}_{2} \mathrm{O}_{5}-50 \mathrm{P}_{2} \mathrm{O}_{5}{ }^{20,21}$. Conversely, we can greatly design the properties of $\mathrm{V}_{2} \mathrm{O}_{5}$ based glass by controlling the amount of $\mathrm{P}_{2} \mathrm{O}_{5}$ content. To design compatible properties for various applications, understanding the glass structure is crucial. Structures of $\mathrm{V}_{2} \mathrm{O}_{5}$ glass and $(100-x) \mathrm{V}_{2} \mathrm{O}_{5}-x \mathrm{P}_{2} \mathrm{O}_{5}(\mathrm{VP} x)$ glasses have been widely studied by using spectrometry techniques ${ }^{22,23}$ and diffraction techniques ${ }^{24-26}$. The results for VP $x$ glasses obtained by using a Fourier transform infrared spectrometer (FT-IR) indicate a structural change from $\mathrm{V}_{2} \mathrm{O}_{5}$ - to $\beta$-VOPO $\mathrm{VOP}_{4}$-like structures around $x=\sim 25^{22}$. The valence states and structure model of $x=40-70$ glass obtained from X-ray photoelectron spectroscopy (XPS) data suggested that this model consisted of a mixture of vanadate phosphate phases, including $\mathrm{V}_{2} \mathrm{O}_{5}, \mathrm{VOPO}_{4},(\mathrm{VO})_{2} \mathrm{P}_{2} \mathrm{O}_{7}, \mathrm{VO}\left(\mathrm{PO}_{3}\right)$ and $\mathrm{V}\left(\mathrm{PO}_{3}\right)_{3}{ }^{23}$. $\mathrm{X}$-ray and neutron diffraction measurements conclude that $\mathrm{V}$-O structural units undergo complex changes as the amount of $\mathrm{V}_{2} \mathrm{O}_{5}$ content decreases ${ }^{25}$. According to an analysis, short-range structural units change from a $\mathrm{VO}_{4+1}$ trigonal pyramid for $x=0, \mathrm{VO}_{4+1}$ trigonal bipyramid and $\mathrm{VO}_{5+1}$ square pyramid for $x=27$ and $\mathrm{VO}_{5+1}$ square pyramid for $x=27-50$ to a $\mathrm{VO}_{5+1}$ square pyramid of $\beta-\mathrm{VOPO}_{4}$ and $\mathrm{VO}_{6}$ distorted octahedron of $(\mathrm{VO})_{2} \mathrm{P}_{2} \mathrm{O}_{7}$ for $x=50$. In addition, the average $\mathrm{V}-\mathrm{O}$ coordination number $\left(N_{\mathrm{V}-\mathrm{O}}\right)$ for $\mathrm{VP} x$ glasses changes from 4.5 $(x=10)$ to $5.1(x=50)$ as the amount of $\mathrm{V}_{2} \mathrm{O}_{5}$ content decreases ${ }^{25}$.

Nevertheless, the structure-property relationship in VPx glass is still unclear; in particular, the water durability, thermal stability and hardness of this glass are important properties for practical application. One reason is that the coordination environment and valence of vanadium atoms are still unknown. The other is that the nature of network formation in the glass still has not been well revealed. In this article, we report on the properties and atomic structures of VP $x$ glasses characterized by reverse Monte Carlo (RMC) modelling based on neutron/ synchrotron X-ray diffraction data and extended X-ray absorption fine structure (EXAFS) data measured at the $\mathrm{V}-\mathrm{K}$ absorption edge. In addition, we used Raman and ${ }^{51} \mathrm{~V}$ magic angle spinning (MAS) nuclear magnetic resonance (NMR) spectroscopy to determine the connectivity of $\mathrm{PO}_{4}$ tetrahedra and the coordination number of pentavalent $\mathrm{VO}_{x}$ polyhedra, respectively. On the basis of state-of-the art experimental data aided by a data-driven modelling technique, we discuss the relationship between several properties and glass structures with a special focus on the coordination environment and valence of vanadium atoms.

\section{Results}

Glass properties. Glass compositions, the ratio of $\mathrm{V}^{4+} / \mathrm{V}_{\text {total }}$, densities and melting temperatures of $\mathrm{VP} x$ glass samples are summarized in Table 1 . The $\mathrm{V}^{4+} / \mathrm{V}_{\text {total }}$ ratio of the prepared samples increased as the amount of $\mathrm{P}_{2} \mathrm{O}_{5}$ increased. This trend is supported by the shift in the energy of the absorption edge of the X-ray absorption near-edge spectroscopy (XANES) spectra at the V-K edge (Fig. S1) and is consistent with the results of a previous study ${ }^{20}$. However, the values of the previous study differed from those of this study ${ }^{22}$ because the results were affected greatly by the melting conditions.

The glass transition temperature $T_{\mathrm{g}}$ and crystallization temperature $T_{\mathrm{c}}$ determined from differential thermal analysis (DTA) curves of these samples are shown in Fig. 1a,b and are summarized in Table 1. It is demonstrated from Fig. $1 \mathrm{~b}$ that these characteristic temperatures and thermal stability $\Delta T=T_{\mathrm{c}}-T_{\mathrm{g}}$ increased as the $\mathrm{P}_{2} \mathrm{O}_{5}$ amount increased, that $\mathrm{P}_{2} \mathrm{O}_{5}$ is an element for improving thermal stability in the $\mathrm{V}_{2} \mathrm{O}_{5}$ glass system. In particular, no crystallization peak was observed in the VP44 glass, and the glass softened and flowed to the melting temperature without crystallization. The normalized weight loss in water and Vickers microhardness of these samples, shown in Fig. 1c, suggest that the water durability improved drastically, whilst the glass hardened as the $\mathrm{P}_{2} \mathrm{O}_{5}$ amount increased. The atomic number densities and apparent molar volume of $O$ ions for these samples are shown in Fig. 1d. It was confirmed that the atomic number density increased, whereas the apparent molar volume of $\mathrm{O}$ ions decreased as the amount of $\mathrm{P}_{2} \mathrm{O}_{5}$ increased. Both indicate that the packing density of atoms increased with the addition of $\mathrm{P}_{2} \mathrm{O}_{5}$. Indeed, the atomic number density and apparent molar volume of $\mathrm{O}$ ions for crystalline $\mathrm{V}_{2} \mathrm{O}_{5}$ were $0.0779 \AA^{-3}$ and $10.83 \mathrm{~cm}^{3} \mathrm{~mol}^{-1}$, respectively, suggesting that the packing densities of these glass samples were smaller than that of crystalline $\mathrm{V}_{2} \mathrm{O}_{5}$.

Diffraction and EXAFS data. Data on X-ray structure factors, $S^{\mathrm{X}}(Q)$, neutron total structure factors, $S^{\mathrm{N}}(Q)$ and EXAFS $k^{3} \chi(k)$ measured at the $\mathrm{V}-K$ edge for a series of $\mathrm{VP} x$ glasses are summarized in Fig. 2a-c, respectively. It is confirmed that all samples are homogeneous, because we cannot observe any small angle scattering 
a

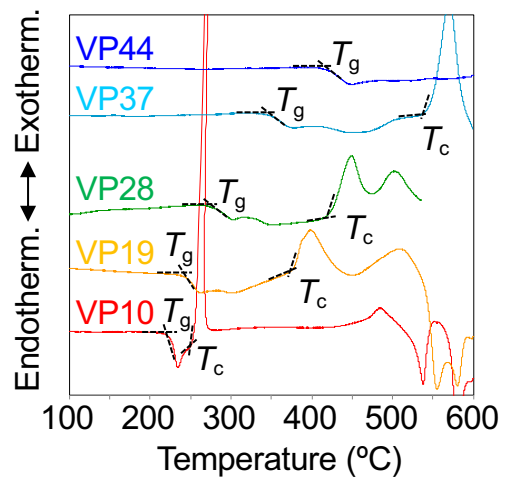

c

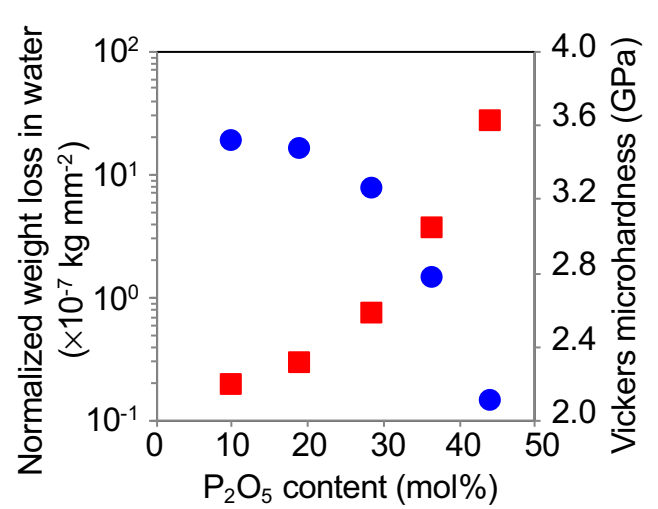

Vickers microhardness

- Weight loss in water

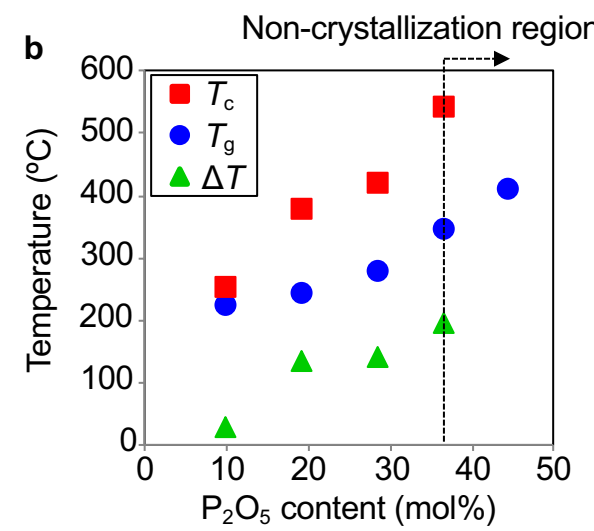

d

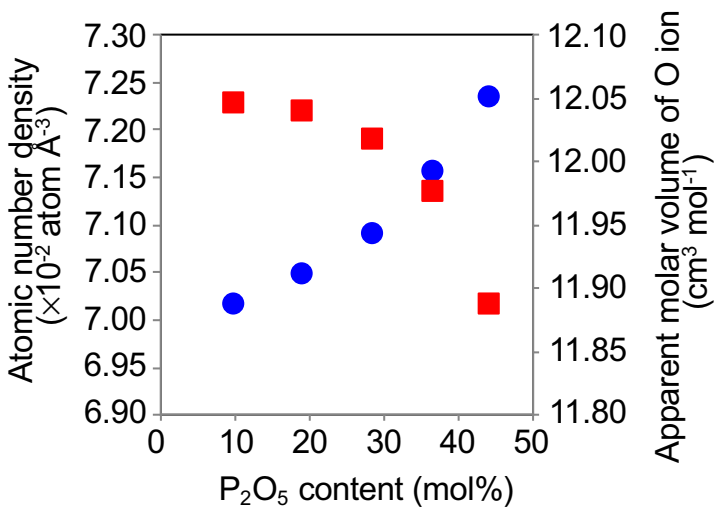

Apparent molar volume of $\mathrm{O}$ ion Atomic number density

Figure 1. Characterization of VPx glasses. (a) Differential thermal analysis curves. (b) Glass transition temperatures and crystallization temperatures. (c) Normalized weight loss in water and Vickers microhardness. (d) Atomic number densities and apparent molar volume of oxygen ion. In VP44 glass, no crystallization peak was observed until glass melted.

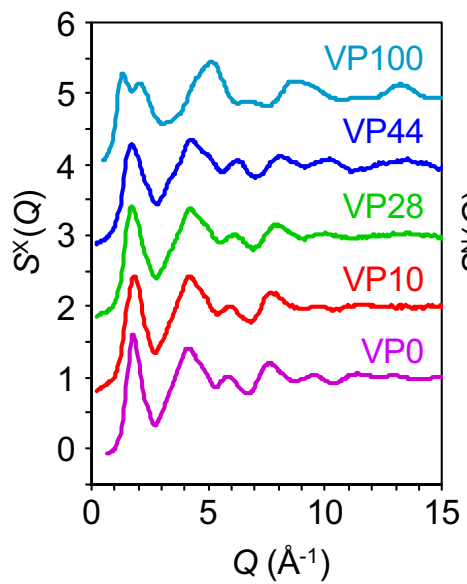

b

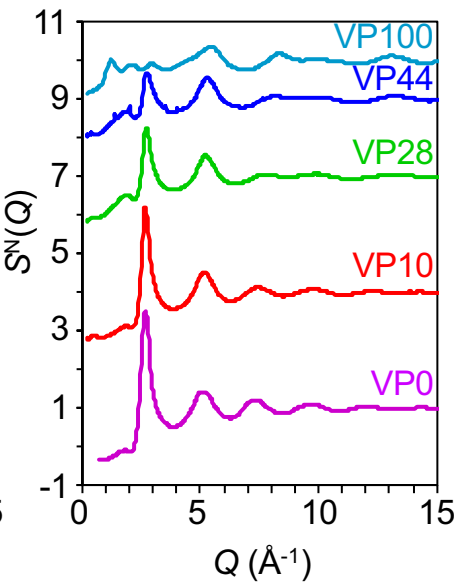

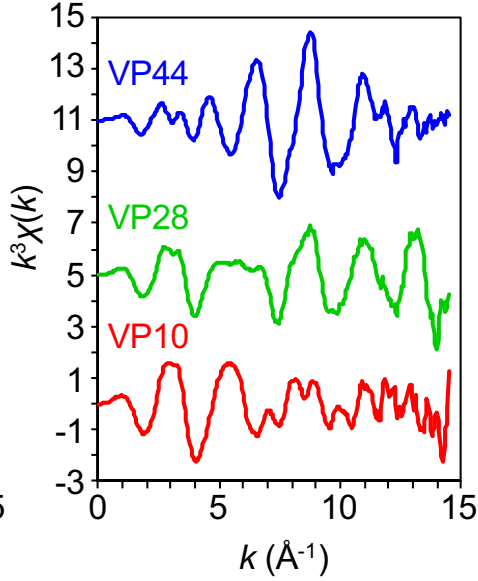

Figure 2. X-ray/neutron diffraction and EXAFS data in reciprocal space for VP $x$ glasses. (a) X-ray total structure factors, $S^{\mathrm{X}}(Q)$. (b) Neutron total structure factors, $S^{\mathrm{N}}(Q)$. (c) EXAFS $k^{3} \chi(k)$ measured at the V-K edge.

at $Q<1 \AA^{-1}$ in Fig. 2a,b. Three-peak structure was observed for the neutron $S^{\mathrm{N}}(Q)$ for VP100 [glassy $\left.(g)-\mathrm{P}_{2} \mathrm{O}_{5}\right]^{26}$ glass, for which we can assign the peak at $Q=1.25 \AA^{-1}$ and that at $Q=2.1 \AA^{-1}$ to a split first sharp diffraction peak $(\mathrm{FSDP})^{27}$, and the peak at $Q=2.95 \AA^{-1}$ to the principal peak $(\mathrm{PP})^{27}$. A split FSDP was not observed for glassy 


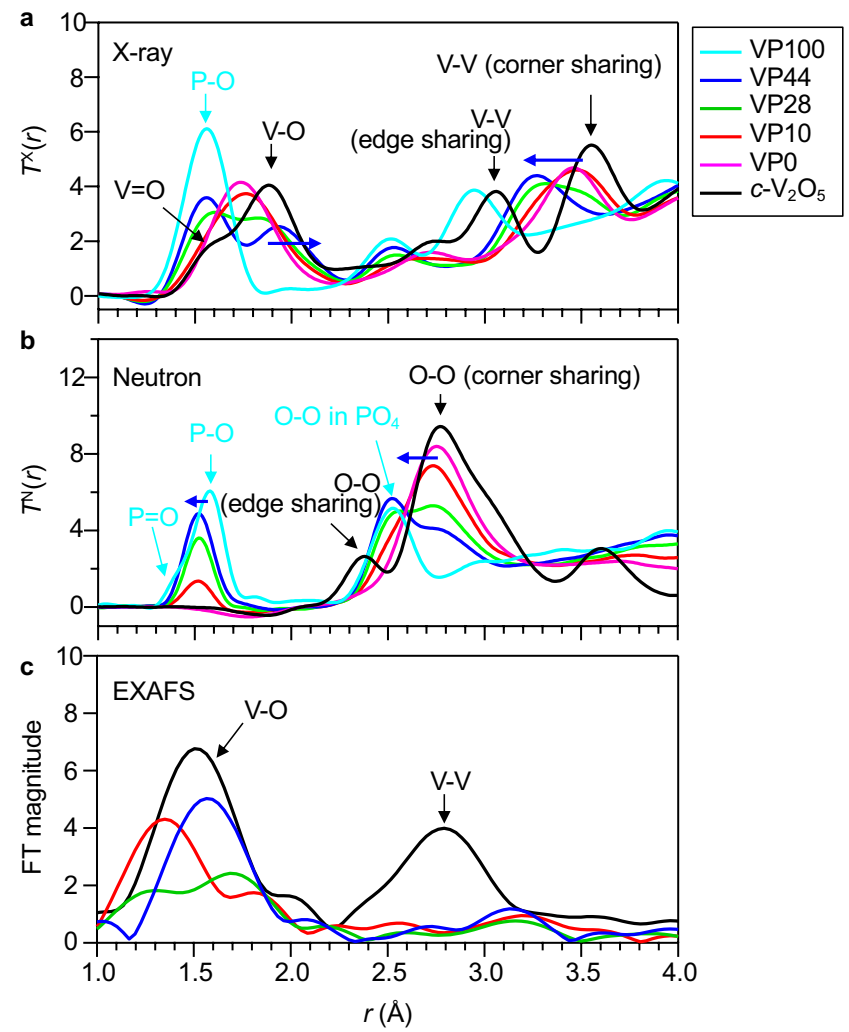

Figure 3. X-ray/neutron diffraction and EXAFS data in real space for VPx glasses together with $c-\mathrm{V}_{2} \mathrm{O}_{5}$ data. (a) X-ray total correlation functions, $T^{\mathrm{X}}(r)$. (b) Neutron total correlation functions, $T^{\mathrm{N}}(r)$. (c) Fouriertransformed (FT) EXAFS spectra for VP $x$ glasses. Black, $c-\mathrm{V}_{2} \mathrm{O}_{5}$; Purple, VP0 glass ${ }^{30}$; Red, VP10 glass; Green, VP28 glass; Blue, VP44 glass; Cyan, VP100 glass ${ }^{26,29}$.

(g) $-\mathrm{SiO}_{2}$ nor glassy $(\mathrm{g})-\mathrm{GeO}_{2}{ }^{28}$, but it was observed for the VP100 glass due to the formation of a $\mathrm{Q}^{3}$ network, in which a phosphorous atom has three bridging oxygen atoms and one bridging oxygen atom. In contrast, we observed only a two-peak structure (FSDP at $Q=1.4 \AA^{-1}$ and PP at $Q=2.1 \AA^{-1}$ ) in the X-ray $S^{\mathrm{X}}(Q)$ for the VP100 glass ${ }^{29}$ because a PP was not observed in the X-ray data due to small weighting factors of oxygen-related correlations for X-rays. Intriguingly, this complicated peak structure disappeared in the other VP $x$ glasses, and it showed a sharp PP at $Q \sim 2.7 \AA^{-1}$ in the neutron $S^{\mathrm{N}}(Q)$ and a relatively sharp FSDP at $Q \sim 1.8 \AA^{-1}$ in the X-ray $S^{\mathrm{X}}(Q)$. The EXAFS data measured at the $\mathrm{V}-K$ edge differed substantially, suggesting that the local environment of $\mathrm{V}$ atoms changed with the glass composition.

The X-ray total correlation functions, $T^{\mathrm{X}}(r)$ and neutron total correlation functions, $T^{\mathrm{N}}(r)$, for a series of $\operatorname{VP} x$ glasses are shown in Fig. 3a,b, respectively, together with the data for crystalline $(c-) \mathrm{V}_{2} \mathrm{O}_{5}$. We can see an excellent contrast between the X-ray and neutron diffraction data because X-rays are sensitive to vanadium, whilst oxygen can be easily detected with neutrons, and it is very difficult to detect vanadium with neutrons. In addition, it is possible to detect both $\mathrm{P}-\mathrm{O}$ and $\mathrm{V}-\mathrm{O}$ correlations with $\mathrm{X}$-rays, as can be seen in the Fig. 3a, where a tiny negative V-O correlation peak can be observed at $r=1.7 \AA$ in the neutron $T(r)$. Indeed, only oxygen atoms can be detected with neutrons, and this allows us to observe both corner-sharing and edge-sharing $\mathrm{O}-\mathrm{O}$ correlations in $c-\mathrm{V}_{2} \mathrm{O}_{5}$. The most striking feature in the X-ray $T(r)$ is the big difference in $\mathrm{V}-\mathrm{O}$ correlation peaks between the VP0 glass [glassy $(g)-\mathrm{V}_{2} \mathrm{O}_{5}$ ] and $c-\mathrm{V}_{2} \mathrm{O}_{5}$. In the case of $c-\mathrm{V}_{2} \mathrm{O}_{5}$, both $\mathrm{V}-\mathrm{O}$ and $\mathrm{V}=\mathrm{O}$ bonds were clearly distinguished, whilst such a doublet feature was not observed in the VP0 glass. Moreover, it was found that the bond length of $\mathrm{V}-\mathrm{O}$ increased, whereas $\mathrm{V}-\mathrm{V}$ correlations and O-O correlations in the corner sharing $\mathrm{VO}_{x}$ polyhedra, and the $\mathrm{P}-\mathrm{O}$ distance decreased as the $\mathrm{P}_{2} \mathrm{O}_{5}$ fraction increased. These results are consistent with the results reported by Hoppe et al. for the VP27 and VP50 glasses ${ }^{25}$, indicating that the structural units of $\mathrm{VO}_{x}$ and $\mathrm{PO}_{4}$ polyhedra and the connectivity of $\mathrm{VO}_{x}-\mathrm{VO}_{x}$ and $\mathrm{VO}_{x}-\mathrm{PO}_{4}$ in each glass change with the glass composition. Figure $3 \mathrm{c}$ shows Fourier-transformed (FT) EXAFS spectra for the VPx glasses, in which significant composition-dependent modification of the local environment around the $\mathrm{V}$ atoms was observed in real space, too.

Structural model of the glasses. We performed RMC modelling on the basis of experimental data to uncover the relationship between glass structures and properties. As can be seen in Fig. S2, RMC-modelled X-ray $S^{\mathrm{X}}(Q)$, neutron $S^{\mathrm{N}}(Q)$ and V-K edge EXAFS $k^{3} \chi(k)$ data for the VP0 $\left(g-\mathrm{V}_{2} \mathrm{O}_{5}\right)^{30}, \mathrm{VP} 10, \mathrm{VP} 28, \mathrm{VP} 44$, and VP100 $\left(g-\mathrm{P}_{2} \mathrm{O}_{5}\right)^{31}$ glasses agreed well with experimental data. Figure 4 compares the partial structure factors, $S_{i j}(Q)$, of a series of VP $x$ glasses calculated from the RMC models. First of all, we address partial structures in the VP0 $\left(g-\mathrm{V}_{2} \mathrm{O}_{5}\right)$ and VP100 $\left(g-\mathrm{P}_{2} \mathrm{O}_{5}\right)$ glasses. It is well known that the FSDP of network formers, e.g., $g$ - $\mathrm{SiO}_{2}$ and $g-\mathrm{GeO}_{2}$, shows up a positive peak in each $S_{i j}(Q)^{28}$. However, the FSDP of the $S_{\mathrm{PP}}(Q)$ and $S_{\mathrm{PO}}(Q)$ was a doublet ${ }^{31}$, and both 

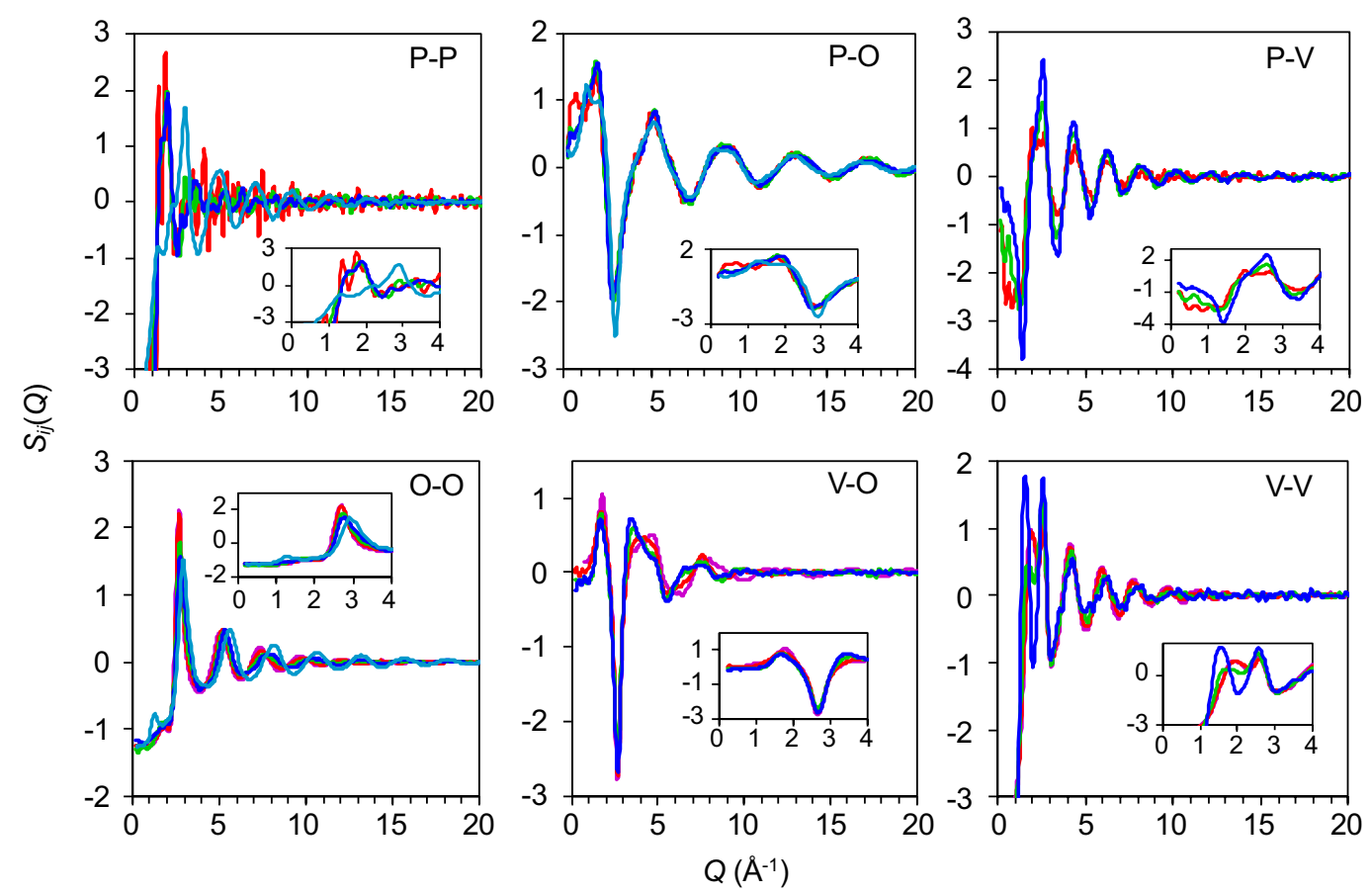

-VP100 VP44 VP28 VP10 -VP0

Figure 4. RMC-generated partial structure factors, $S_{i j}(Q)$, for VP $x$ glasses. Purple, VP0 glass; Red, VP10 glass; Green, VP28 glass; Blue, VP44 glass; Cyan, VP100 glass ${ }^{31}$.

the X-ray and neutron $S(Q)$ did not exhibit a well-defined FSDP for VP100 glass. The reason for this is due to the different length scale that arose from both the P-O bonds $(1.58 \AA)$ and $\mathrm{P}=\mathrm{O}$ bonds $(1.43 \AA)$ in the glass (see Fig. 3b), as discussed by Hoppe ${ }^{26}$. In comparison, a sharp positive FSDP observed at $Q \sim 1.8 \AA^{-1}$ for three $S_{i j}(Q)$ in the VP0 glass, which is related to a $\mathrm{V}-\mathrm{O}$ correlation peak that is relatively symmetrical in comparison with the VP0 glass. Other interesting behaviour is the very sharp negative and positive peaks observed at $Q=1.38 \AA^{-1}$ and $Q=2.60 \AA^{-1}$ in the $S_{\mathrm{P}-\mathrm{V}}(\mathrm{Q})$ of the VP44 glass, suggesting that the network was formed by the interplay between $\mathrm{PO}_{4}$ tetrahedra and $\mathrm{VO}_{x}$ polyhedra.

Partial pair-distribution functions, $g_{i j}(r)$, of a series of VP $x$ glasses calculated from the RMC models are shown in Fig. 5. The first P-O correlation peaks observed at $r=1.6 \AA$ for the VP10, VP28 and VP44 glasses were more symmetrical in comparison with the VP100 glass, suggesting that electrons were more delocalized in the VP10, VP28 and VP44 glasses. A significant composition-dependent change was observed for $g_{\mathrm{O}-\mathrm{O}}(r), g_{\mathrm{V}-\mathrm{O}}(r)$ and $g_{\mathrm{V}-\mathrm{V}}(r)$, and it was confirmed that this reflected the changes in the experimental $T(r)$. The first P-V correlation peak observed at $3.2 \AA$ became sharp as the $\mathrm{P}_{2} \mathrm{O}_{5}$ fraction increased, which was in line with the behaviour in $Q$ space, suggesting the interplay between $\mathrm{PO}_{4}$ tetrahedra and $\mathrm{VO}_{x}$ polyhedra in forming the network.

The average coordination numbers calculated up to $2.5 \AA$ and the ratio of edge-sharing $\mathrm{VO}_{x}$ polyhedra calculated from the RMC models are summarized in Table 2. The oxygen-cation coordination number $N_{\mathrm{O}-\mathrm{M}}(\mathrm{M}=\mathrm{V}$, $\mathrm{P})$, the $\mathrm{V}$-O coordination number $\mathrm{N}_{\mathrm{V}-\mathrm{O}}$ and the ratio of edge-sharing $\mathrm{VO}_{x}$ polyhedra increased as the amount of $\mathrm{P}_{2} \mathrm{O}_{5}$ increased. It is worth mentioning that $15 \%$ of $\mathrm{VO}_{x}$ polyhedra were edge-shared in the VP44 glass, which is outside of Zachariasen's rule ${ }^{1}$. These behaviours are consistent with the fact that the packing density of atoms in glass increased as the $\mathrm{P}_{2} \mathrm{O}_{5}$ fraction increased. The atomic configurations together with the cavity volume of a series of VPx glasses are shown in Fig. 6. It is noted that the cavity volume increased as the amount of $\mathrm{P}_{2} \mathrm{O}_{5}$ increased, whilst packing density increased.

The $\mathrm{Q}^{n}$ distribution of $\mathrm{V}$ and $\mathrm{P}$ species calculated from the RMC models are shown in Fig. 7a,b. Although the $\mathrm{Q}^{n}$ distribution of $\mathrm{V}$ species shifted to a smaller number of $n$ as the amount of $\mathrm{P}_{2} \mathrm{O}_{5}$ increased, the $\mathrm{V}$ species had a high proportion at $n \geq 2$ (Fig. 7a). In comparison, the $\mathrm{P}$ species were almost isolated $\mathrm{PO}_{4}\left(\mathrm{Q}^{0}\right)$ tetrahedra not only in the VP10 glass but also in the VP44 glass, as shown in Fig. 7b. These behaviours are supported by the Raman spectra as shown in Fig. S3, in which a peak assigned to $\mathrm{Q}^{0}$ was observed for the VP10 and VP44 glasses. The ring statistics of VPx glasses are shown in Fig. 7c. It was demonstrated that the normalized number of V-O rings decreased as the amount of $\mathrm{P}_{2} \mathrm{O}_{5}$ increased, whereas $\mathrm{P}-\mathrm{O}$ rings did not form in the range of glasses VP10 to VP44. In contrast, the normalized number of M-O rings increased as the amount of $\mathrm{P}_{2} \mathrm{O}_{5}$ increased. These results strongly indicate that the network former of the $\mathrm{VP} x$ glasses changed from $\mathrm{VO}_{x}-\mathrm{VO}_{x}$ networks to the interplay between $\mathrm{VO}_{x}$ and $\mathrm{PO}_{4}$ for the VP28 and VP44 glasses. These changes in the network structure and edge-shared $\mathrm{VO}_{x}$ polyhedra were clearly visible in the three-dimensional atomic configurations obtained from the RMC models, as shown in Fig. 7d,e. 

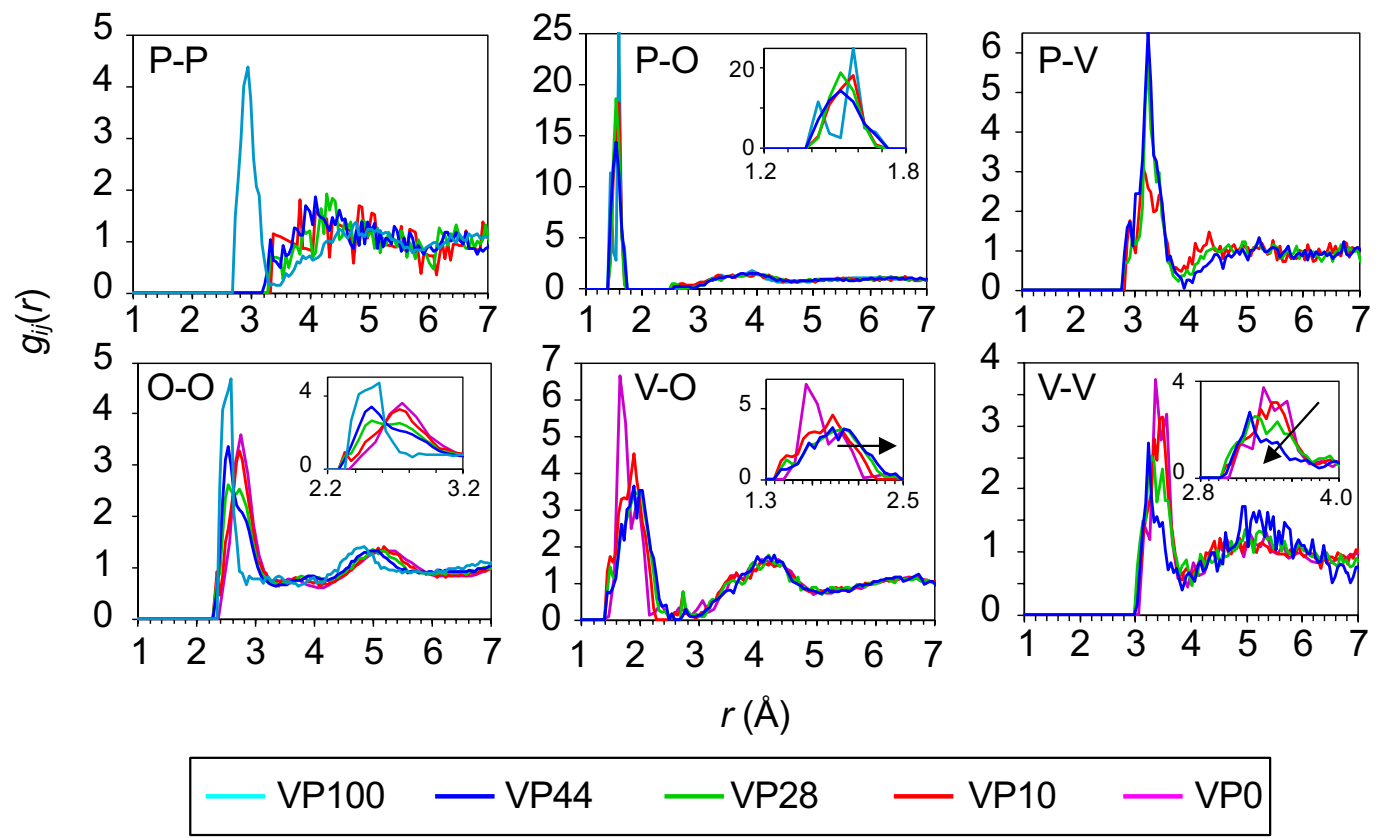

Figure 5. Short-range structural analysis on RMC-generated models for VP $x$ glasses. Partial pair-distribution functions, $g_{i j}(r)$. Purple, VP0 glass; Red, VP10 glass; Green, VP28 glass; Blue, VP44 glass; Cyan, VP100 glass ${ }^{31}$.

a
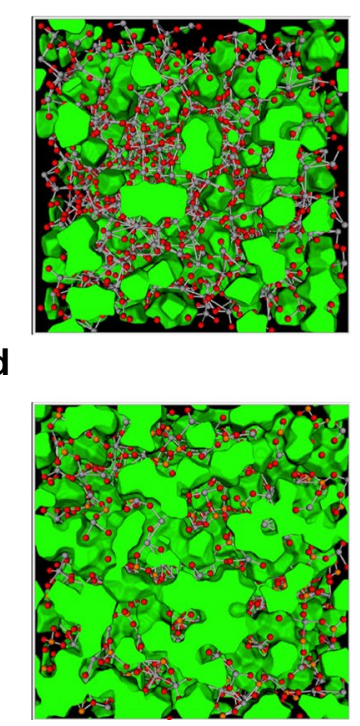

b

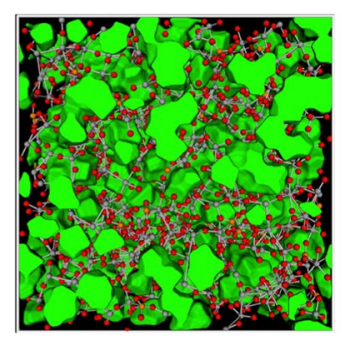

e

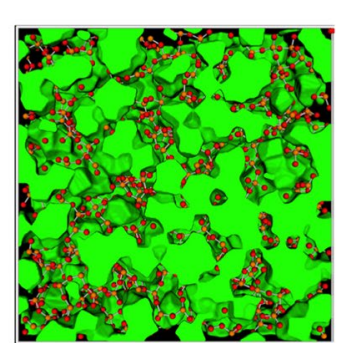

C

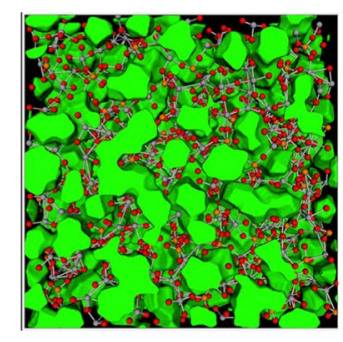

Oxygen

Vanadium

Phosphorus

Cavity

Figure 6. Cavity analysis. (a-e) RMC-generated atomic configurations with cavities for (a) VP0, (b) VP10, (c) VP28, (d) VP44 and (e) VP100 glasses. (f) Cavity volume as a function of $\mathrm{P}_{2} \mathrm{O}_{5}$ content.

\begin{tabular}{|c|c|c|c|c|c|c|c|}
\hline \multirow[b]{2}{*}{ Composition } & \multicolumn{6}{|c|}{ Coordination numbers $(r<2.5 \AA)$} & \multirow{2}{*}{$\begin{array}{l}\text { Edge-sharing } \\
\text { rate of } \mathrm{VO}_{x}(\%)\end{array}$} \\
\hline & $N_{\text {P-O }}$ & $N_{\text {O-p }}$ & $N_{\text {O-o }}$ & $N_{\mathrm{V}-\mathrm{O}}$ & $N_{\mathrm{O}-\mathrm{v}}$ & $N_{\mathrm{O}-\mathrm{M}}(\mathrm{M}=\mathrm{V}, \mathrm{P})$ & \\
\hline $\mathrm{VP0}\left(\mathrm{V}_{2} \mathrm{O}_{5}\right)$ & None & None & 0.27 & 4.43 & 1.77 & 1.77 & 1.1 \\
\hline VP10 & 4.00 & 0.16 & 0.66 & 4.46 & 1.64 & 1.80 & 1.5 \\
\hline VP28 & 3.99 & 0.48 & 1.21 & 4.52 & 1.40 & 1.88 & 5.0 \\
\hline VP44 & 3.98 & 0.80 & 1.43 & 4.75 & 1.22 & 2.02 & 15.0 \\
\hline $\mathrm{VP} 100\left(\mathrm{P}_{2} \mathrm{O}_{5}\right)$ & 3.99 & 1.60 & 2.07 & None & None & 2.07 & None \\
\hline
\end{tabular}

Table 2. Coordination numbers of VP $x$ glasses obtained by RMC models. 
a

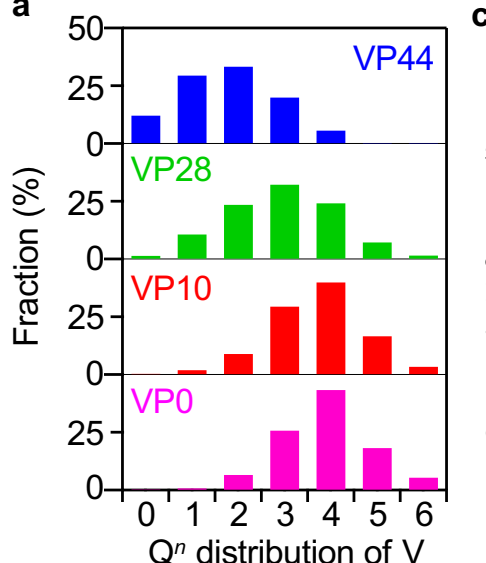

b

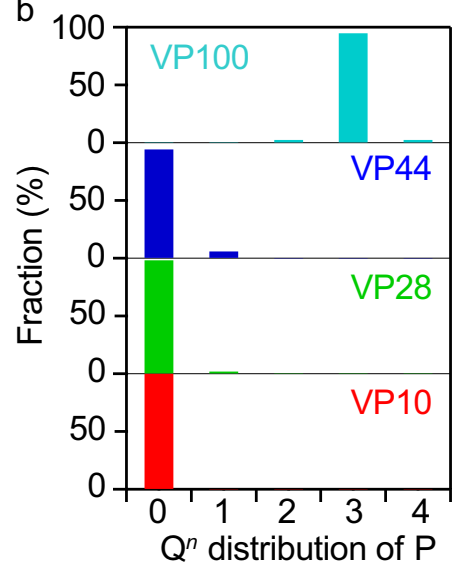

C

ธิ

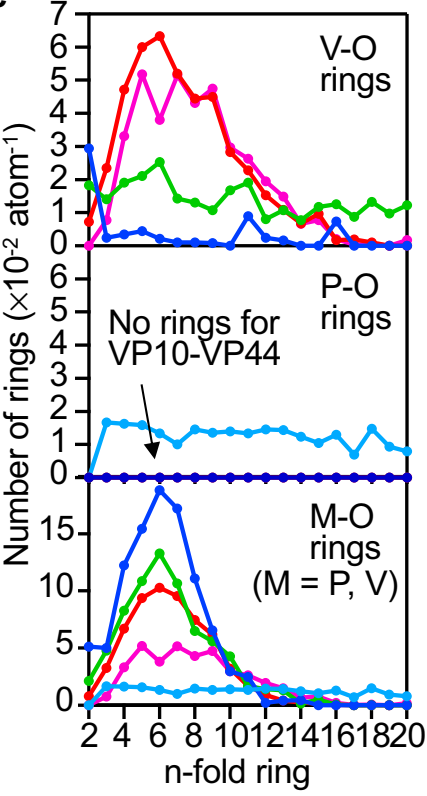

d

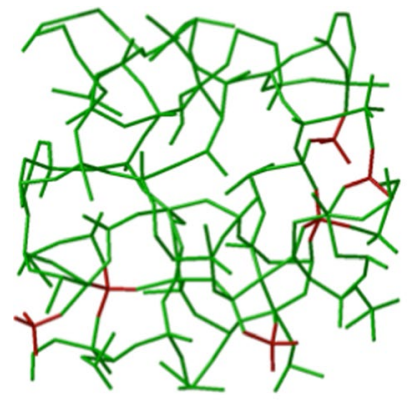

e

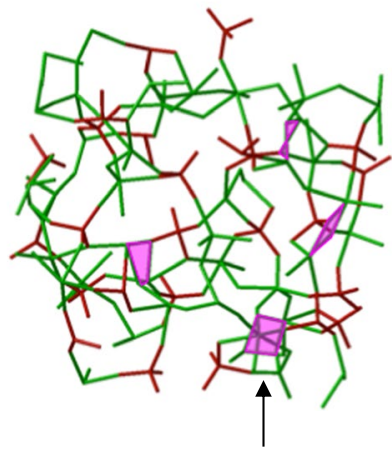

Edge-shared $\mathrm{VO}_{\mathrm{x}}$ polyhedra

Figure 7. Connectivity and ring statistics of $\mathrm{VO}_{x}$ and $\mathrm{PO}_{4}$ polyhedra. $(\mathbf{a}, \mathbf{b}) \mathrm{Q}^{n}$ distribution of $\mathrm{V}$ and $\mathrm{P}$ species obtained by RMC modelling. (c) Normalized numbers of - V-O-rings, -P-O-rings and -M-O-rings $(M=P, V)$ in VP $x$ glasses. Purple, VP0 glass; Red, VP10 glass; Green, VP28 glass; Blue, VP44 glass; Cyan, VP100 glass. (d,e) Atomic configurations of (d) VP10 and (e) VP44 glasses are obtained from the RMC models. Green and redcoloured bond represents $\mathrm{V}-\mathrm{O}$ bond and $\mathrm{P}-\mathrm{O}$ bond, respectively.

a

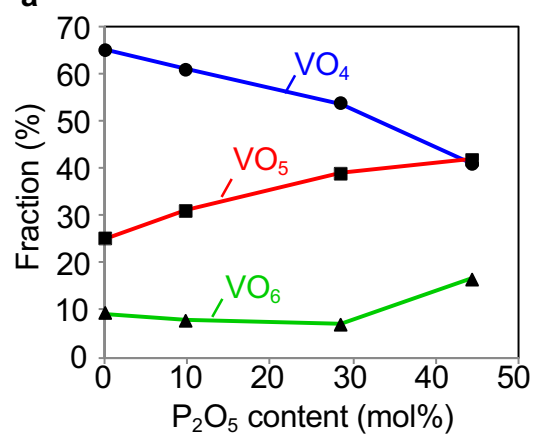

b

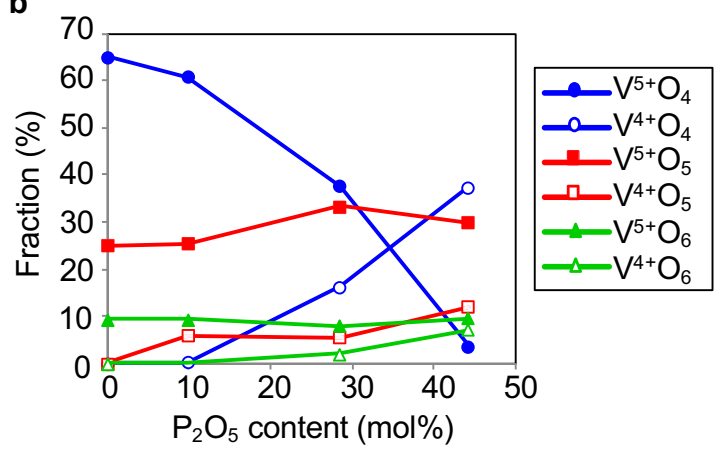

Figure 8. Distribution of oxygen coordination number and valence of vanadium. (a) Total fraction of $\mathrm{VO}_{4}$, $\mathrm{VO}_{5}$ and $\mathrm{VO}_{6}$ units obtained by RMC modelling. (b) Fraction of $\mathrm{V}^{5+} \mathrm{O}_{4-6}$ and $\mathrm{V}^{4+} \mathrm{O}_{4-6}$ units calculated by RMC modelling and ${ }^{51} \mathrm{~V}$ NMR spectroscopy.

The fraction of $\mathrm{VO}_{x}$ polyhedra derived from the RMC models is shown in Fig. 8a. The figure clearly shows that the majority of short-range structural units in the $\mathrm{VP} x$ glasses consisted of $\mathrm{VO}_{4}$ and $\mathrm{VO}_{5}$ units. It was also found that the fraction of $\mathrm{VO}_{4}$ units decreased, whilst the fraction of $\mathrm{VO}_{5}$ units increased systematically as the amount of $\mathrm{P}_{2} \mathrm{O}_{5}$ increased. Taking the vanadium valence into account, $\mathrm{VO}_{x}$ polyhedra were divided into six units, $\mathrm{V}^{4+} \mathrm{O}_{4-6}$ and $\mathrm{V}^{5+} \mathrm{O}_{4-6}$. To obtain information on the local structure around the $\mathrm{V}^{5+}$ in the $\mathrm{VP} x$ glasses, NMR spectroscopic measurements were performed. ${ }^{51} \mathrm{~V}$ NMR spectroscopy can selectively detect the diamagnetic $\mathrm{V}^{5+}$ state because the $\mathrm{V}^{4+}$ state cannot be analysed directly due to its paramagnetism. The ${ }^{51} \mathrm{~V}$ MAS-NMR spectra of the VPx 
glasses are shown in Fig. S4. The peaks observed at around $-750,-540,-490$ and $-300 \mathrm{ppm}$ can be assigned to symmetric- $\mathrm{V}^{5+} \mathrm{O}_{4}\left(s-\mathrm{VO}_{4}\right)$, distorted- $\mathrm{V}^{5+} \mathrm{O}_{4}\left(d-\mathrm{VO}_{4}\right), \mathrm{V}^{5+} \mathrm{O}_{6}\left(\mathrm{VO}_{6}\right)$ and $\mathrm{V}^{5+} \mathrm{O}_{5}$ units $\left(\mathrm{VO}_{5}\right)$, respectively ${ }^{32-34}$. The fractions of these units, as calculated from the area of each peak, are summarized in Table S1. It is suggested for the $\mathrm{V}^{5+}$ state in the VP $x$ glasses that the fraction of $\mathrm{V}^{5+} \mathrm{O}_{4}$ units decreased as the amount of $\mathrm{P}_{2} \mathrm{O}_{5}$ increased, whereas the fraction of $\mathrm{V}^{5+} \mathrm{O}_{5}$ units increased. The fractions of $\mathrm{V}^{5+} \mathrm{O}_{4-6}$ and $\mathrm{V}^{4+} \mathrm{O}_{4-6}$ units calculated from the RMC models, ${ }^{51} \mathrm{~V}$ NMR spectroscopy and the fraction of $\mathrm{V}^{4+} / \mathrm{V}_{\text {total }}$ are shown in Fig. $8 \mathrm{~b}$. The result clearly indicates that the unusually small coordination number of $\mathrm{V}^{4+} \mathrm{O}_{4}$ units existed in the $\mathrm{VP} x$ glasses and the fraction increased as the amount of $\mathrm{P}_{2} \mathrm{O}_{5}$ increased, although it has been suggested for the $\mathrm{V}^{4+}$ state in glass that only $\mathrm{V}^{4+} \mathrm{O}_{5}$ or $\mathrm{V}^{4+} \mathrm{O}_{6}$ units are taken the same as crystals due to the larger ionic radius of $\mathrm{V}^{4+35-38}$. Such unusually small coordination numbers in oxide glass are also reported for $\mathrm{MgO}-\mathrm{SiO}_{2}{ }^{39}, \mathrm{CaO}-\mathrm{Al}_{2} \mathrm{O}_{3}{ }^{40}$ and $\mathrm{ZnO}-\mathrm{P}_{2} \mathrm{O}_{5}{ }^{41}$ glass systems, and, hence, it is suggested that this may be a characteristic feature in some oxide glasses with atypical network formers.

\section{Discussion}

We set out to model the glass structure to understand the water durability, thermal stability and hardness, which are important in practical applications. The water durability of VP $x$ glasses improves as the amount of $\mathrm{P}_{2} \mathrm{O}_{5}$ increases, even though VP0 $\left(g-\mathrm{V}_{2} \mathrm{O}_{5}\right)$ and VP100 $\left(g-\mathrm{P}_{2} \mathrm{O}_{5}\right)$ glasses readily dissolve into water ${ }^{31,42,43}$. Gin et al. reported on the water durability of glass divided into several stages ${ }^{44}$. This improvement of VP $x$ glasses in terms of water durability was determined to be due to the suppression of the hydrolysis process, which is affected by the structure of $\mathrm{VO}_{x}$ and $\mathrm{PO}_{4}$ polyhedra and the valence of vanadium. The cavity volume in the glass did not seem to significantly affect the water durability because, when the cavity volume increased, the water durability improved. Regarding the structure of $\mathrm{VO}_{x}$ polyhedra and valence of vanadium, Nabavi et al. suggested that the $\mathrm{V}^{5+} \mathrm{O}_{4}$ units in amorphous $\mathrm{V}_{2} \mathrm{O}_{5}$ are highly reactive towards water, whereas the $\mathrm{V}^{5+} \mathrm{O}_{5}$ units in crystalline $\mathrm{V}_{2} \mathrm{O}_{5}$ are not. Moreover, they also suggested that the water durability increased when the number of $\mathrm{V}^{5+} \mathrm{O}_{4}$ units decreased, which implies that water durability is affected by $\mathrm{V}-\mathrm{O}$ coordination ${ }^{35}$. Our results also show that there is a clear correlation between normalized weight loss in water and the fraction of $\mathrm{V}^{5+} \mathrm{O}_{4}$ units in all cations (see Fig. S5). In other words, we suggest that $\mathrm{V}^{4+} \mathrm{O}_{4}$ units are stable against water, whilst $\mathrm{V}^{5+} \mathrm{O}_{4}$ units are highly reactive towards water. We conclude that this might be affected by the polarizability of $\mathrm{VO}_{x}$ polyhedra, as in the case of $\mathrm{PO}_{4}$ polyhedra. Therefore, the increase in edge-sharing $\mathrm{VO}_{x}$ polyhedra might improve the water durability. Regarding the structure of $\mathrm{PO}_{4}$ polyhedra, several papers reported that phosphate glass that has $\mathrm{PO}_{4}$ tetrahedra with $\mathrm{Q}^{0}$ or $\mathrm{Q}^{1}$ structures shows good water durability, suggesting that the low polarizability in $\mathrm{PO}_{4}$ tetrahedral units makes it hard to attract polar water molecules ${ }^{45-47}$. Therefore, the reason that the water durability improved in the range of glasses VP0 to VP44 is because the structures of the $\mathrm{PO}_{4}$ tetrahedral units were only $\mathrm{Q}^{0}$ and $\mathrm{Q}^{1}$ structures, unlike the $\mathrm{Q}^{3}$ structures in the VP100 glass. Hence, we conclude that the mechanism for improving water durability by mixing materials with poor water durability is the change in the structure of $\mathrm{VO}_{x}$ and $\mathrm{PO}_{4}$ units toward units with low polarizability that have good water durability. As reported by Feltz et al., if the amount of $\mathrm{P}_{2} \mathrm{O}_{5}$ is further increased in VPx glasses, the water durability decreases because the connectivities of $\mathrm{PO}_{4}$ tetrahedra might change into $\mathrm{Q}^{2}$ and/or $\mathrm{Q}^{3}$ structures ${ }^{20}$. In other words, our results imply that the water durability of VP $x$ glasses can be improved by changing the interconnection of $\mathrm{VO}_{x}$ and $\mathrm{PO}_{4}$ polyhedra and the valence of vanadium, for example, by adding additives. This presumption is supported by the fact that the water durability of VP $x$ glasses improves with the addition of $\mathrm{Sb}_{2} \mathrm{O}_{3}$, which causes an increase in the ratio of $\mathrm{V}^{4+} / \mathrm{V}_{\text {total }}{ }^{21,48}$.

The thermal stability, an indirect indicator of glass forming ability, of VP $x$ glasses also improves as the amount of $\mathrm{P}_{2} \mathrm{O}_{5}$ increases, which indicates that the driving force of crystallization is reduced. Since a driving force arises from the difference in chemical potential between the glass state and crystalline state, our result indicates that the difference becomes smaller as the amount of $\mathrm{P}_{2} \mathrm{O}_{5}$ increases. We conclude that there are two reasons for this. One reason is that the atomic structure of the glasses is very far away from the conventional oxide glasses classified by Zachariasen ${ }^{1}$ and $\mathrm{Sun}^{2}$, and the similarity with a crystalline structure increases as the amount of $\mathrm{P}_{2} \mathrm{O}_{5}$ increases. The similarity between glass and crystal is often discussed for the fast phase-change materials used for DVD/Blu-ray media, where the topology in terms of the ring-size distribution between glass and crystal is similar, whilst coordination in the glassy phase is significantly lower than that in the crystal phase. Therefore, it is concluded that this similarity is the crucial reason for the rapid phase change between two phases ${ }^{49}$. Indeed, the increased packing density and large fraction of edge-sharing in the glassy state are a remarkable signature of $\mathrm{P}_{2} \mathrm{O}_{5}$ rich glass. Accordingly, these behaviours demonstrate that the similarity between glass and crystal beyond the nearest neighbour distance (for example, polyhedral connection and atomic packing density) is rather important for the glass properties because the first V-O coordination number and the valence of vanadium of VP $x$ glasses are different from those of crystal. In other words, this indicates that the similarity beyond the nearest neighbour distance is important for decreasing the difference in chemical potential between the glassy state and crystalline state. The other reason is the high ratio of $\mathrm{V}^{4+} / \mathrm{V}_{\text {total }}$ in the VP $x$ glasses. Sakurai et al. also reported that the thermal stability of VP $x$ glasses improves as the amount of $\mathrm{P}_{2} \mathrm{O}_{5}$ increases, but that of their VPx glasses is significantly lower than that of our VP $x$ glasses ${ }^{22}$. Although the packing densities of their VP $x$ glasses were not mentioned in ref. ${ }^{22}$, the ratio of $\mathrm{V}^{4+} / \mathrm{V}_{\text {total }}$ in their $\mathrm{VP} x$ glasses was lower than that of our VPx glasses. Accordingly, we suggest that the high ratio of $\mathrm{V}^{4+} / \mathrm{V}_{\text {total }}$ is an important factor for improving thermal stability, too. However, it is still not certain whether $\mathrm{V}^{4+}$ states themselves reduce the chemical potential between glass and crystal or that they increase the atomic packing density and edge-sharing $\mathrm{VO}_{x}$ polyhedra.

The hardness of the VP $x$ glasses also improves as the amount of $\mathrm{P}_{2} \mathrm{O}_{5}$ increases. We conclude that this should be explained by an increased packing density associated with a higher V-O/O-M coordination number and increase in edge-sharing $\mathrm{VO}_{x}$ polyhedra. Indeed, Rosales-Sosa et al. reported that a high atomic packing density and dissociation energy per unit volume of components increases the values of hardness and the elastic modulus ${ }^{50}$. We calculated the atomic packing density in Fig. S6. It was found that the increase in $\mathrm{P}_{2} \mathrm{O}_{5}$ content caused the glass structure to have a higher packing density with increased $\mathrm{V}-\mathrm{O} / \mathrm{O}-\mathrm{M}$ coordination numbers and increase 
in edge-shared $\mathrm{VO}_{x}$ polyhedra. The dissociation energy per unit volume of components should increase with the number of bonds per unit volume of components. Furthermore, the reduction in vanadium ions might affect the dissociation energy, whilst the cavity volume in glass should be independent of hardness because it does not affect the packing density and dissociation energy.

In addition, we have previously reported that the thermal expansion coefficients of VP $x$ glasses did not change significantly despite an increased glass transition temperature as the amount of $\mathrm{P}_{2} \mathrm{O}_{5}$ increased ${ }^{21}$. Generally, the thermal expansion coefficient of glass materials increased as the glass transition temperature decreased. Such an anomalous coefficient was also identified with the network configuration in $\mathrm{ZnO}-\mathrm{P}_{2} \mathrm{O}_{5}$ glass systems ${ }^{41}$. We calculated the fractions of M-O ring distributions as shown in Fig. S7. The distribution remained the same in the range of glasses VP10 to VP44. Hence, our results imply that this anomalous thermal expansion coefficient was related to the fractions of the distributions only because of a structural feature that does not change in the range of glasses VP10 to VP44. These results for the structure-property relationship demonstrate that the properties of glass are strongly affected by the structure and valence of network forming cations.

\section{Conclusion}

In this article, we discussed the relationship between the properties and atomic structure of $\mathrm{V}_{2} \mathrm{O}_{5}-\mathrm{P}_{2} \mathrm{O}_{5}$ glass as characterized by RMC modelling on the basis of neutron and synchrotron X-ray data. The present findings indicate that the structure and valence of network formers is important for designing their properties. Adding $\mathrm{P}_{2} \mathrm{O}_{5}$ causes the packing density of atoms to increase and the amount of vanadium ions to decrease in $\mathrm{V}_{2} \mathrm{O}_{5}$-rich glass, resulting in a glass structure that is associated with an increase in edge-sharing $\mathrm{VO}_{x}$ polyhedra. We find that these are important for improving the water durability, thermal stability and hardness. In particular, the valence and structural change of vanadium affect the change in the water durability and thermal stability. We are confident that the unusually small coordination number of $\mathrm{V}^{4+}$ is especially important for water durability and that the similarity between glass and crystal beyond the nearest neighbour distance is important for thermal stability. The results presented in this study are a significant advance in understanding the fundamental properties of glass materials. Furthermore, this work paves the way towards glass sealing materials being completely lead-free and cathode materials for secondary batteries being improved.

\section{Materials and Methods}

Sample preparation. Glass samples with a nominal molar composition of $(100-x) \mathrm{V}_{2} \mathrm{O}_{5}-x \mathrm{P}_{2} \mathrm{O}_{5}$ were synthesized by melt quenching of $\mathrm{V}_{2} \mathrm{O}_{5}$ and $\mathrm{P}_{2} \mathrm{O}_{5}$ powders (Kojundo Chemical Laboratory Co., Ltd.). $100 \mathrm{~g}$ of the mixture was melted in a platinum crucible and kept at melting temperature for one hour. The molten glass was cast onto a stainless-steel plate at $100^{\circ} \mathrm{C}$. The prepared glass samples were annealed at $10^{\circ} \mathrm{C}$ higher than the glass transition temperature and slowly cooled at $1^{\circ} \mathrm{C} \mathrm{min}^{-1}$ for $40 \mathrm{~min}$ to relieve residual internal stress. $\mathrm{V}_{2} \mathrm{O}_{5}$ glass was synthesized by using a twin roller method. The oxide powder was melted at $800^{\circ} \mathrm{C}$ for 5 min in a platinum crucible and then rapidly quenched by rotating rollers.

Characterization. The cation compositions of the resulting material were determined by wavelength dispersive X-Ray fluorescence spectrometers (Rigaku, ZSX Primus II). The resulting material was fully amorphous, and this was confirmed by X-ray diffraction (XRD) using a diffractometer system equipped with a monochromatic $\mathrm{Cu} \mathrm{K} \alpha$ radiation source (Rigaku, RINT-2000). The fraction of the reduced amount of $\mathrm{V}$ ion $\left(\left[\mathrm{V}^{4+}\right] /\left[\mathrm{V}_{\text {total }}\right]\right)$ was estimated by measuring the quantities of pentavalent vanadium ions $\left[\mathrm{V}^{5+}\right]$ and total vanadium ions $\left[\mathrm{V}_{\text {total }}\right]$ by oxidation-reduction titration, assuming that the $\mathrm{V}$ ions in the glass consisted of $\mathrm{V}^{5+}$ and $\mathrm{V}^{4+}$. The densities of the glass samples were measured by using a dry pycnometer (Micromeritics, AccuPyc II 1340). The atomic number densities of these samples were calculated from the density and $\mathrm{V}^{4+} / \mathrm{V}_{\text {total }}$ ratio. The apparent molar volumes of $\mathrm{O}$ ions were also calculated from the density and $\mathrm{V}^{4+} / \mathrm{V}_{\text {total }}$ ratio by using the formula described by Drake et al. ${ }^{51}$. The glass transition temperature $\left(T_{\mathrm{g}}\right)$ and crystallization temperature $\left(T_{\mathrm{c}}\right)$ were measured by using differential thermal analysis (DTA) (Advance Riko, DT-1500) at a heat rate of $5^{\circ} \mathrm{C} \mathrm{min}^{-1}$. The weight loss in water at $70^{\circ} \mathrm{C}$ for $30 \mathrm{~min}$ for the glass sample plates was measured to determine the water resistance. Vickers microhardness measurements were made on the sample surfaces at room temperature by using an auto hardness test system (Matsuzawa, AMT-X7FS) with an accuracy of $\pm 0.04 \mathrm{GPa}$. A load was applied for $0.98 \mathrm{~N}, 15 \mathrm{~s}$.

Structural analysis of glass. High-energy X-ray diffraction experiments (HEXRD) were carried out at room temperature by using the BL04B2 beamline of SPring- $8^{52}$. The incident X-ray energy was $61.6 \mathrm{keV}$ as obtained from a $\mathrm{Si}(220)$ crystal monochromator. Diffraction patterns of the samples, placed in a silica glass tube, were measured in a transmission geometry. The collected data were corrected by using a standard program $^{52}$. X-ray absorption fine structure (XAFS) experiments were carried out by using the BL14B2 beamline of SPring- $8^{53}$. The XAFS samples were ground with boron nitride and made into pellets. V-K edge spectra were measured by using a $\mathrm{Si}(111)$ double-crystal monochromator in transmission mode. Ionization chambers were used to measure the intensity of the incident and transmitted X-rays, and the quick scan technique (QXAFS) was used for this measurement. These spectra were normalized and analysed by using Athena ${ }^{54}$. Time-of-flight neutron diffraction (ND) experiments were conducted by using the total scattering spectrometer NOVA at the BL21 beamline of the Materials and Life Science Experimental Facility (MLF), Japan Proton Accelerator Research Complex (J-PARC) ${ }^{55}$. The samples were placed in a cylindrical vanadium cell (6 mm in diameter). The observed scattering intensities for the samples were corrected for instrumental background, absorption of samples and cell ${ }^{56}$, and multiple ${ }^{57}$ and incoherent scatterings and then normalized by the incident beam profile, which obtained from the scattering intensity for a vanadium rod. ${ }^{51} \mathrm{~V}$ spectra were measured at $11.7 \mathrm{~T}$ (JEOL, ECA-500 FT-NMR). A NaVO 3 aqueous solution $\left(0.16 \mathrm{~mol} \mathrm{dm}^{-3}\right)$ was taken as a reference $(\delta=-574.28 \mathrm{ppm})$. 
The pulse delay was $1 \mathrm{~s}$. Raman spectra were recorded by using a LabRam spectrometer (Jobin-Yvon). A laser with an emission wavelength of $514.5 \mathrm{~nm}$ and a power of $0.2 \mathrm{~mW}$ was used.

Structural modelling. The RMC modelling was performed on an ensemble of 3500, 4138, 3989 and 3818 particles for VP0, VP10, VP28 and VP44 glass, respectively. The starting configurations were generated by hard-sphere Monte Carlo simulations with constraints applied to avoid physically unrealistic structures. The constraints on the P-O connectivity were that all phosphorus atoms were coordinated for four oxygen atoms for atomic distances of up to $1.7 \AA$. X-ray $S^{\mathrm{X}}(Q)$, neutron $S^{\mathrm{N}}(Q)$ and $k^{3} \chi(k)$ EXAFS data measured at the V-K edge were fitted simultaneously by using RMC $++\operatorname{code}^{58}$. EXAFS back scattering tables were obtained from FEFF calculations ${ }^{59}$. The ring statistics were calculated by primitive rings analysis ${ }^{60-62}$ using R.I.N.G.S. code ${ }^{63}$. Cavity analysis was carried out by employing pyMolDyn code ${ }^{64}$. The cut-off distance $r_{\mathrm{c}}$ for cavity calculation was $2.3 \AA$.

\section{Data availability}

The datasets generated during and/or analysed during the current study are available from the corresponding author upon reasonable request.

Received: 13 June 2019; Accepted: 6 April 2020;

Published online: 28 April 2020

\section{References}

1. Zachariasen, W. H. The atomic arrangement in glass. J. Am. Chem. Soc. 54, 3841-3851 (1932).

2. Sun, K. H. Fundamental condition of glass formation. J. Am. Chem. Soc. 30, 277-281 (1947).

3. Mehrer, H. Diffusion in solids: fundamentals, methods, materials, diffusion-controlled processes, 522-523 (Springer, 2007).

4. Denton, E. P., Rawson, H. \& Stanworth, J. E. Vanadate glass. Nature 173, 1030-1032 (1954).

5. Munakata, M. Electrical conductivity of high vanadium phosphate glass. Solid-State Electron 1, 159-163 (1960).

6. Linsley, G. S., Owen, A. E. \& Hayatee, F. M. Electronic conduction in vanadium phosphate glasses. J. Non-Cryst. Solids 4, 208-219 (1970).

7. Frazier, L. L. \& France, P. W. Compositional dependence of the electrical conductivity of vanadium phosphate glass. J. Phys. Chem. Solids 38, 801-808 (1977).

8. Roling, B. \& Funke, K. Polaronic transport in vanadium phosphate glasses. J. Non-Cryst. Solids 212, 1-10 (1997).

9. Afyon, S. et al. New high capacity cathode materials for rechargeable Li-ion batteries: vanadate-borate glasses. Sci. Rep. 4, 7113 (2014).

10. Uchaker, E. et al. Better than crystalline: amorphous vanadium oxide for sodium-ion batteries. J. Mater. Chem. A 2, 18208-18214 (2014).

11. Arthur, T. S. et al. Amorphous $\mathrm{V}_{2} \mathrm{O}_{5}-\mathrm{P}_{2} \mathrm{O}_{5}$ as high-voltage cathodes for magnesium batteries. Chem. Commun. 51, 15657-15660 (2015).

12. Aoyagi, T. et al. Electrochemical properties and in-situ XAFS observation of $\mathrm{Li}_{2} \mathrm{O}-\mathrm{V}_{2} \mathrm{O}_{5}-\mathrm{P}_{2} \mathrm{O}_{5}-\mathrm{Fe}_{2} \mathrm{O}_{3}$ quaternary-glass and crystallized-glass cathodes. J. Non-Cryst. Solids 453, 28-35 (2016).

13. Naito, T. et al. Lead-free low-melting and semiconductive vanadate glass applicable to low-temperature sealing. Jpn, J. Appl. Phys. 50, 088002 (2011).

14. Naito, T. et al. Influence of $\mathrm{P}_{2} \mathrm{O}_{5} / \mathrm{TeO}_{2}$ composition ratio on the physical properties of $\mathrm{V}_{2} \mathrm{O}_{5}-\mathrm{P}_{2} \mathrm{O}_{5}-\mathrm{TeO}_{2}$ glasses for lead-free lowtemperature sealing. J. Ceram. Soc. Jpn. 121, 452-456 (2013).

15. Kubo, S. et al. Characteristic evaluation of lead-free sealing glasses composed of $\mathrm{V}_{2} \mathrm{O}_{5}-\mathrm{MnO}_{2}-\mathrm{KPO}_{3}-\mathrm{CuO}$. Kagaku Kogaku Ronbunshu 31, 137-142 (2014).

16. Matuo, F. et al. Development of $\mathrm{V}_{2} \mathrm{O}_{5}-\mathrm{ZnO}-\mathrm{TeO}_{2}-(\mathrm{ZrO})_{2}\left(\mathrm{HPO}_{4}\right)_{2}$ sealing glass with low melting point and low thermal expansion properties. Kagaku Kogaku Ronbunshu 41, 253-258 (2015).

17. Cho, S. J. \& Lee, K. Additional study on the laser sealing of dye-sensitized solar-cell-panels using $\mathrm{V}_{2} \mathrm{O}_{5}$ and $\mathrm{TeO}_{2}$ containing glass. J. Korean Ceram. Soc. 52, 103-107 (2015).

18. Li, H. et al. Structure of $\mathrm{V}_{2} \mathrm{O}_{5}-\mathrm{P}_{2} \mathrm{O}_{5}-\mathrm{Sb}_{2} \mathrm{O}_{3}-\mathrm{Bi}_{2} \mathrm{O}_{3}$ glass. Int. J. Min. Met. Mater. 19, 628-635 (2012).

19. Wang, F. et al. Investigation of the melting characteristic, forming regularity and thermal behavior in lead-free $\mathrm{V}_{2} \mathrm{O}_{5}-\mathrm{B}_{2} \mathrm{O}_{3}-\mathrm{TeO} \mathrm{O}_{2}$ low temperature sealing glass. Mater. Lett. 67, 196-198 (2012).

20. Feltz, A. \& Unger, B. Redox reactions in condensed oxide systems II. Variation of the structure of vanadium phosphate glasses in dependence on the oxidation state of vanadium. J. Non-Cryst. Solids 72, 335-343 (1985).

21. Naito, T., Namekawa, T., Yamada, S. \& Maeda, K. Effects of composition and additives on water durability in $\mathrm{V}_{2} \mathrm{O}_{5}-\mathrm{P}_{2} \mathrm{O}_{5}$ glass system. J. Ceram. Soc. Jpn. 97, 834-841 (1989).

22. Sakurai, Y. \& Yamaki, J. Correlation between microstructure and electrochemical behavior of amorphous $\mathrm{V}_{2} \mathrm{O}_{5}-\mathrm{P}_{2} \mathrm{O}_{5}$ in lithium cells. J. Electrochem. Soc. 135, 791-796 (1988).

23. Khattak, G. D., Mekki, A. \& Wenger, L. E. X-ray photoelectron spectroscopy (XPS) and magnetic susceptibility studies of vanadium phosphate glasses. J. Non-Cryst. Solids 355, 2148-2155 (2009).

24. Hoppe, U. \& Kranold, R. A reverse Monte Carlo study of the structure of vitreous $\mathrm{V}_{2} \mathrm{O}_{5}$. Solid State Commun. 109, 625-630 (1999).

25. Hoppe, U. et al. Structure of $\mathrm{V}_{2} \mathrm{O}_{5}-\mathrm{P}_{2} \mathrm{O}_{5}$ glasses by X-ray and neutron diffraction. J. Non-Cryst. Solids 358, 328-336 (2012).

26. Hoppe, U., Walter, G., Barz, A., Stachel, D. \& Hannon, A. C. The P-O bond lengths in vitreous $\mathrm{P}_{2} \mathrm{O}_{5}$ probed by neutron diffraction with high real-space resolution. J. Phys. Condens. Matter 10, 261-270 (1998).

27. Salmon, P. S., Martin, R. A., Mason, P. E. \& Cuello, G. J. Topological versus chemical ordering in network glasses at intermediate and extended length scales. Nature 435, 75-78 (2005).

28. Kohara, S. \& Suzuya, K. Intermediate-range order in vitreous $\mathrm{SiO}_{2}$ and $\mathrm{GeO}_{2}$. J. Phys. Condens. Matter 17, S77-S86 (2005).

29. Hoppe, U., Kranold, R., Barz, A., Stachel, D. \& Neuefeind, J. The structure of vitreous $\mathrm{P}_{2} \mathrm{O}_{5}$ studied by high-energy X-ray diffraction. Solid State Commun. 115, 559-562 (2000).

30. Munemura, H., Tanaka, S., Maruyama, K. \& Misawa, M. Structural study of $\mathrm{Li}_{2} \mathrm{O}-\mathrm{V}_{2} \mathrm{O}_{5}$ glasses by neutron and X-ray diffraction. J. Non-Cryst. Solids 312-314, 557-560 (2002).

31. Brazhkin, V. V. et al. Densified low-hygroscopic form of $\mathrm{P}_{2} \mathrm{O}_{5}$ glass. J. Mater. Chem. 21, 10442-10447 (2011).

32. Eckert, H. \& Wachs, L. E. Solid-state ${ }^{51}$ V NMR structural studies on supported vanadium(V) oxide catalysts: vanadium oxide surface layers on alumina and titania supports. J. Phys. Chem. 93, 6796-6805 (1989).

33. Lapina, O. B., Mastikhin, V. M., Simonova, L. G. \& Bulgakova, Yu. O. Characterization of surface species of supported $\mathrm{V}_{2} \mathrm{O}_{5}-\mathrm{Al}_{2} \mathrm{O}_{3}$ catalysts by ${ }^{51}$ V NMR. J. Mol. Catal. 69, 61-73 (1991).

34. Miller, J. M. \& Lakshmi, L. J. $\mathrm{V}_{2} \mathrm{O}_{5}$ catalysts supported on $\mathrm{Al}_{2} \mathrm{O}_{3}-\mathrm{SiO}_{2}$ mixed oxide: ${ }^{51} \mathrm{~V},{ }^{1} \mathrm{H}$ MAS solid-state NMR, DRIFTS and methanol oxidation studies. Appl. Catal. A 190, 197-206 (2000).

35. Nabavi, M., Sanchez, C. \& Livage, J. Structure and properties of amorphous $\mathrm{V}_{2} \mathrm{O}_{5}$. Philos. Mag. B 63, $941-953$ (1991). 
36. Sakida, S., Hayakawa, S. \& Yoko, T. ${ }^{125} \mathrm{Te}$ and ${ }^{51} \mathrm{~V}$ static NMR study of $\mathrm{V}_{2} \mathrm{O}_{5}-\mathrm{TeO}_{2}$ glasses. J. Phys. Condens. Matter 12 , 2579-2595 (2000).

37. Rozier, P., Burian, A. \& Cuello, G. J. Neutron and X-ray scattering studies of $\mathrm{Li}_{2} \mathrm{O}-\mathrm{TeO}_{2}-\mathrm{V}_{2} \mathrm{O}_{5}$ glasses. J. Non-Cryst. Solids 351, 632-639 (2005)

38. Krins, N. et al. Structural and electrical properties of tellurovanadate glasses containing $\mathrm{Li}_{2} \mathrm{O}$. Solid State Ionics 177, 3147-3150 (2007).

39. Kohara, S. et al. Relationship between topological order and glass forming ability in densely packed enstatite and forsterite composition glasses. Proc. Natl. Acad. Sci. USA 108, 14780-14785 (2011).

40. Akola, J. et al. Network topology for the formation of solvated electrons in binary $\mathrm{CaO}-\mathrm{Al}_{2} \mathrm{O}_{3}$ composition glasses. Proc. Natl. Acad. Sci. USA 110, 10129-10134 (2013).

41. Onodera, Y. et al. Formation of metallic cation-oxygen network for anomalous thermal expansion coefficients in binary phosphate glass, Nat. Commun. 8, 15449 (2017).

42. Gharbi, N. et al. A new vanadium pentoxide amorphous phase. J. Non-Cryst. Solids 46, 247-257 (1981).

43. Meyer, K., Barz, A. \& Stachel, D. Effects of atmospheric humidity on the infrared reflectivity of vitreous $\mathrm{P}_{2} \mathrm{O}_{5}$ and ultraphosphate glasses. J. Non-Cryst. Solids 191, 71-78 (1995).

44. Gin, S. et al. An international initiative on long-term behaviour of high-level nuclear waste glass. Mater. Today 16, 243-248 (2013).

45. Cha, J., Kubo, T., Takebe, H. \& Kuwabara, M. Compositional dependence of properties of SnO- $\mathrm{P}_{2} \mathrm{O}_{5}$ glasses. J. Ceram. Soc. Jpn. 116, 915-919 (2008).

46. Fukui, S., Sakida, S., Benino, Y. \& Nanba, T. Effect of $\mathrm{Nb}_{2} \mathrm{O}_{5}$ addition to SnO- $\mathrm{P}_{2} \mathrm{O}_{5}$ glass. J. Ceram. Soc. Jpn. 120, 530-533 (2012)

47. Saitoh, A. et al. Zero photoelastic and water durable $\mathrm{ZnO}-\mathrm{SnO}-\mathrm{P}_{2} \mathrm{O}_{5}-\mathrm{B}_{2} \mathrm{O}_{3}$ glasses. APL Mater. 3, 046102 (2015).

48. Naito, T., Namekawa, T., Katoh, A. \& Maeda, K. Effect of $\mathrm{Sb}_{2} \mathrm{O}_{3}$ addition on water durability of $\mathrm{V}_{2} \mathrm{O}_{5}-\mathrm{P}_{2} \mathrm{O}_{5}$ glass. J. Ceram. Soc. Jpn. 100, 685-690 (1992).

49. Matsunaga, T. et al. From local structure to nanosecond recrystallization dynamics in AgInSbTe phase-change materials. Nat. Mater. 10, 129-134 (2011).

50. Rosales-Sosa, G. A., Masuno, A., Higo, Y. \& Inoue, H. Crack-resistant $\mathrm{Al}_{2} \mathrm{O}_{3}-\mathrm{SiO}_{2}$ glasses. Sci. Rep. 6, 23620 (2016).

51. Drake, C. F., Stephan, J. A. \& Yates, B. The densities of $\mathrm{V}_{2} \mathrm{O}_{5} / \mathrm{P}_{2} \mathrm{O}_{5}$ glasses and the oxygen molar volume. J. Non-Cryst. Solids 28, 61-65 (1978).

52. Kohara, S. et al. Structural studies of disordered materials using high-energy X-ray diffraction from ambient extreme conditions. J. Phys. Condens. Matter 19, 506101 (2007).

53. Homma, T. et al. Full-automatic XAFS measurement system of the engineering science research II beamline BL14B2 at SPring-8. AIP Conf. Proc. 1234, 13-16 (2010).

54. Ravel, B. \& Newville, M. ATHENA, ARTEMIS, HEPHAESTUS: data analysis for X-ray absorption spectroscopy using IFEFFIT. J. Synchrotron Radiat. 12, 537-541 (2005).

55. Otomo, T. et al. Fundamental research of hydrogen storage mechanism with high-intensity total diffractometer. KENS Rep. 17, 28-36 (2011)

56. Paalman, H. H. \& Pings, C. J. Numerical evaluation of X-ray absorption factors for cylindrical samples and annular sample cells. J. Appl. Phys. 33, 2635-2639 (1965).

57. Blech, I. A. \& Averbach, B. L. Multiple scattering of neutrons in vanadium and copper. Phys. Rev. 137, A1113-A1116 (1965).

58. Gereben, O., Jóvári, P., Temleitner, L. \& Pusztai, L. A new version of the RMC++ Reverse Monte Carlo programme, aimed at investigating the structure of covalent glasses. J. Optoelectron. Adv. Mater. 9, 3021-3027 (2007).

59. Ankudinov, A. L., Ravel, B., Rehr, J. J. \& Conradson, S. D. Real-space multiple-scattering calculation and interpretation of X-rayabsorption near-edge structure. Phys. Rev. B 58, 7565-7576 (1998).

60. Goetzke, K. \& Klein, H. J. Properties and efficient algorithmic determination of different classes of rings in finite and infinite polyhedral networks. J. Non-Cryst. Solids 127, 215-220 (1991).

61. Yuan, X. \& Cormack, A. N. Efficient algorithm for primitive ring statistics in topological networks. Comp. Mater. Sci. 24, 343-360 (2002).

62. Wooten, F. Structure, odd lines and topological entropy of disorder of amorphous silicon. Acta Cryst. A 58, 346-351 (2002).

63. Le Roux, S. \& Jund, P. Ring statistics analysis of topological networks: new approach and application to amorphous $\mathrm{GeS}_{2}$ and $\mathrm{SiO}_{2}$ systems. Comput. Mater. Sci. 49, 70-83 (2010).

64. Heimbach, I. et al. pyMolDyn: identification, structure, and properties of cavities/vacancies in condensed matter and molecules. J. Comput. Chem. 38, 389-394 (2017).

\section{Acknowledgements}

The synchrotron radiation experiments were performed at BL04B2 and BL14B2 of SPring-8 with the approval of the Japan Synchrotron Radiation Research Institute (JASRI; Proposal Nos. 2012B1720, 2012B1761 and 2013A1801). The neutron diffraction experiment at the Materials and Life Science Experimental Facility of the J-PARC was performed under a user program (Proposal No. 2012B0066). The authors thank Drs. H. Ofuchi and T. Otomo for their assistance in the measurements and data analysis, respectively. The authors also thank M. Ando and S. Kayamori for their assistance in the NMR analysis. It is our great pleasure to thank Profs. U. Hoppe and M. Misawa for providing us with neutron/X-ray diffraction data for $\mathrm{P}_{2} \mathrm{O}_{5}$ glass and neutron diffraction data for $\mathrm{V}_{2} \mathrm{O}_{5}$ glass, respectively. This work was supported by JST PRESTO Grant Number JPMJPR15N4, Japan (S.K.) and the "Materials Research by Information Integration" Initiative ( $\left.\mathrm{MI}^{2} \mathrm{I}\right)$ project of the Support Program for Starting Up Innovation Hub from JST (S.K., Y.O. and S.T.).

\section{Author contributions}

T.A., S.K. and T.N. designed and directed this study. T.A. and T.M. prepared and characterized the samples. S.K., Y.O. and K.O. carried out the synchrotron X-ray diffraction experiment. T.A., M.K., T.O., D.T. and T.U. carried out XAFS measurements and analysed data. T.A., Y.O. and K.S. conducted the neutron diffraction experiment. T.A., S.K. Y.O. and S.T. performed RMC modelling and analysed the results. O.S., T.M., Y.H. and H.T. advised in this study. T.A., S.K. and Y.O. wrote the paper.

\section{Competing interests}

The authors declare no competing interests.

Additional information

Supplementary information is available for this paper at https://doi.org/10.1038/s41598-020-63786-y. 
Correspondence and requests for materials should be addressed to T.A. or S.K.

Reprints and permissions information is available at www.nature.com/reprints.

Publisher's note Springer Nature remains neutral with regard to jurisdictional claims in published maps and institutional affiliations.

(c) Open Access This article is licensed under a Creative Commons Attribution 4.0 International License, which permits use, sharing, adaptation, distribution and reproduction in any medium or format, as long as you give appropriate credit to the original author(s) and the source, provide a link to the Creative Commons license, and indicate if changes were made. The images or other third party material in this article are included in the article's Creative Commons license, unless indicated otherwise in a credit line to the material. If material is not included in the article's Creative Commons license and your intended use is not permitted by statutory regulation or exceeds the permitted use, you will need to obtain permission directly from the copyright holder. To view a copy of this license, visit http://creativecommons.org/licenses/by/4.0/.

(C) The Author(s) 2020 